\title{
Hepatic Lipidosis Due to Obesity in a Free-Living Snake (Boa constrictor amarali)
}

\author{
Nathana Beatriz Martins', Lucas Arthur Ricardo Ferreira', Tainara Santana Galvão da Silva', \\ Ana Carolina de Andrade Mello Cintra de Amorim Alves', André Luiz Quagliatto Santos', \\ Amanda Bizare², Rafael Rocha de Souza ${ }^{2}$ \& Alessandra Aparecida Medeiros ${ }^{3}$
}

\begin{abstract}
Background: Liver performs several important functions to the maintenance of physiological mechanisms. Some liver diseases may directly affect anatomical and physiological aspects of this organ, and may lead to a permanent liver injury. In snakes, the most common causes of liver disease are infections, however, approaches on non-infectious liver diseases are scarce. Therefore, the objective of this study was to describe macroscopically and microscopically liver alterations in a Boa constrictor amarali snake.

Case: A adult male boa (Boa constrictor amarali) snake of $110 \mathrm{~cm}$ of length and weight of $3.270 \mathrm{~kg}$ from free-living conditions, and without previous history was rescued in an urban area and taken by the Environmental Police to the Laboratory for Teaching and Research in Wild Animals (LAPAS) of the Federal University of Uberlândia's (UFU) Veterinary Hospital, in Uberlândia MG, Brazil. The animal died and a significant amount of adipose tissue was found throughout the extension of the coelomic cavity at necropsy, limiting the visualization of its internal organs. Fragments of altered organs were collected and packed in a universal collector containing a 10\% buffered formalin solution. These samples were sent to the Animal Pathology Laboratory (LPA) of the UFU. Macroscopically, the stomach presented a reddish mucosa, and mucous contents. The liver was pale, with a yellowish color and a friable consistency. Microscopically, dilated hepatic sinusoids filled with red blood cells were observed; the hepatocytes were enlarged, and its cytoplasm were filled with vacuoles of varied sizes that did not stain (severe diffuse lipidosis). It was also found occurrence of multifocal areas with loss of tissue architecture, and hepatocytes in karyolysis, charactering necrosis; and a discrete amount of multifocal mononuclear inflammatory infiltrate (multifocal hepatitis).

Discussion: Obesity is connected to the occurrence of hepatic steatosis, since snakes are ectothermic animals that depend on environmental factors to maintain their metabolic rates. Obesity is a common problem in reptiles kept in captivity because they usually have constantly available food and little space to move. However, this was also observed in this study in a free-living animal found in an urbanized environment. Urbanization provides greater availability of food, and the animal does not need to go long distances to find a pray; this causes greater gain of body weight. Reptiles subjected to hot environments lose weight rapidly due to their relatively high metabolic rates. However, when subjected to low temperatures, they have a decrease in metabolism, compromising absorption, digestion, and liver metabolism, which causes fat accumulation. The animal under study is sedentary and it is a marked characteristic of this species; this strengthen the hypothesis that the animal moved little to feed because it was in an environment with high availability of prey. The animal presented accumulation of fat throughout the coelomic cavity, causing the rate of accumulation of triglycerides in the hepatocytes to exceed its metabolic degradation rate, resulting in steatosis. The early diagnosis of hepatic alterations favors the appropriate treatment, allowing the prevention of irreversible damage to this organ, and avoid the animal's death.
\end{abstract}

Keywords: ectotherm, hepatocellular lipidosis, snakes, amaral's boa, hepatic steatosis. 


\section{INTRODUCTION}

Boa constrictor amarali is a non-venomous snake of the Squamata order (Ophidia suborder) with wide distribution in the Brazilian territory [5], especially in the Northeast, Southeast and South regions [14].

Snakes, like other reptiles, are ectothermal animals that depend exclusively on the environment for the maintenance of their physiological, biochemical, and immunological processes. Thus, alterations in growth and reproduction rates are expected considering the seasonal effect, since the seasons affect their total food intake and vulnerability to predators $[2,3,6,15]$.

Liver is a key organ in digestion, and in the metabolism of carbohydrates, lipids and proteins, and promotes processes of detoxification, immunoregulation and vitamin reserve [4]. Liver is the largest deposit of fat tissue and fat reserve in the body [10].

Lipids are normally transported from adipose tissue and gastrointestinal tract to the liver as free fatty acids or chylomicrons, respectively. Excess lipid in the liver is called hepatocellular lipidosis or hepatic steatosis. It occurs when the triglycerides accumulation rate in hepatocytes exceeds their metabolic degradation rate or their release as lipoproteins [11].

Macroscopically, mild steatosis may not be detectable, but livers with detectable steatosis appear enlarged, yellowish, soft, friable, with rounded and wide lobe edges. When incised, the surface of the cut can undergo protrusion, since the liver parenchyma is soft and friable. Microscopically, hepatocytes with lipidosis are vacuolated depending on the severity [11].

In reptiles, several factors may favor the occurrence of hepatic steatosis [9], but the main causes are those related to the metabolic syndrome [8], such as obesity, insulin resistance and hyperlipidemia $[1,12]$.

The objective of this study was to report a case of hepatic steatosis in a free-living Boa constrictor amarali snake, in an obesity situation, and describe macroscopically and microscopically its liver alterations.

\section{CASE}

A adult male adult boa (Boa constrictor amarali) snake popularly known as jibóia-cinzenta in Brazil, with $110 \mathrm{~cm}$ of length and weight of $3.270 \mathrm{~kg}$, and without previous history was rescued from freeliving conditions in an urban area and taken by the Environmental Police to the Laboratory for Teaching and Research in Wild Animals (LAPAS) of the Federal
University of Uberlândia's (UFU) Veterinary Hospital, in Uberlândia MG, Brazil. The animal remained in the institution for clinical evaluation.

During its permanence in the laboratory, it had dysecdysis and scales appearing whitish. A collection was performed with a deep scale scraping. The material was placed in a microscopy slide, and potassium hydroxide was added to clear the sample for visualization of fungal forms. The result of the mycological analysis was negative.

The animal died naturally and the necropsy examination was immediately performed. The main findings by opening of the coelomic cavity were: a significant amount of adipose tissue throughout the extension of the cavity, limiting the visualization of its internal organs; the stomach had a diffusely reddish mucosa and a moderate amount of a transparent mucous; and the liver was enlarged, with a slightly yellowish color, rounded edges and friable consistency.

Fragments of stomach and liver were collected and packed in a universal collector containing a $10 \%$ buffered formalin solution. The samples were sent to the Laboratory of Animal Pathology (LPA) of the UFU. Histological slides were made according to routine techniques and stained with hematoxylin (Harris ${ }^{\circledR}$ Hematoxylin) $^{1}$ and eosin $\left(\text { Yellow Eosin }{ }^{\circledR}\right)^{1}$ [17].

According to the microscopic examination, the stomach had submucosa capillaries filled with red blood cells, with a discrete lymphohistiocytic inflam-

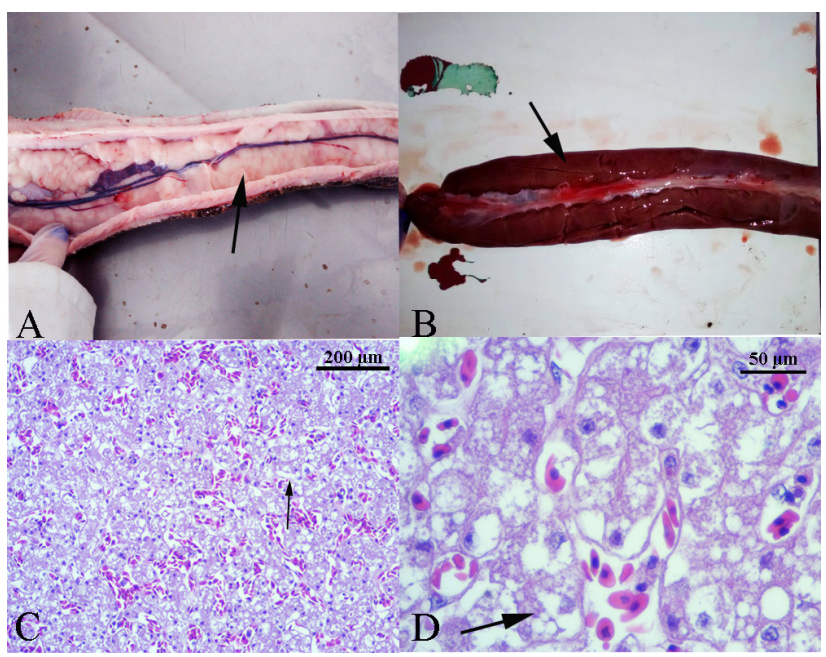

Figure 1. A- Presence of adipose tissue throughout the extension of the coelomic cavity (arrow), limiting the visualization of internal organs. B- Pale liver, with slightly yellowish coloration and friable consistency (arrow). C- Hepatocytes presenting increased volume, with cytoplasm filled by vacuoles of varied sizes that do not stain (arrow). D- Hepatocytes presenting increased volume, with cytoplasm filled by vacuoles of varied sizes that do not stain (arrow). 
matory infiltrate; the mucosa had increased number of goblet cells with increased volume, and cytoplasmic vacuolization (mucosal gastritis).

Microscopically, the hepatic sinusoids were dilated and filled with red blood cells (hyperemia); the hepatocytes were diffusely enlarged, with vacuolated cytoplasm, filled by vacuoles of varied sizes that did not stain (severe diffuse lipidosis). It was observed areas with loss of hepatic tissue architecture, hepatocytes presenting nuclear pyknosis and karyolysis (multifocal coagulative necrosis), and presence of several foci with discrete mononuclear inflammatory infiltrate (multifocal hepatitis).

\section{DISCUSSION}

The snake evaluated in this report was found in an urban environment, with greater availability of food, thus, the animal probably had no need to go long distances to find a pray, which caused it to have a greater weight gain.

Ectotherm - body temperature dependent on the environment and not on internal metabolism - is one of the most important characteristics of reptiles, which affects almost every aspect of their physiology [5]. Moreover, reptiles are heterothermic, thus, they have a wide range of body temperatures depending on environmental conditions. Environmental temperature affects their central body temperature, forage behavior, digestion, nutrient absorption, and metabolic rates [7].

Therefore, the animal's accumulation of fat was probably due to its low predation activity - it had no need to go long distances to find prays in the urban area - and its overfeeding during the winter or times of low temperatures, when its metabolic rate, absorption and digestion decrease.

Reptiles subjected to hot environments lose weight rapidly due to relatively high metabolic rates [7]. However, when subjected to low temperatures, its metabolism decreases, compromising absorption, digestion, and liver metabolic activity, which causes fat accumulation.

Snakes are carnivorous, thus, their main energy sources are protein and fat. They consume about $25 \%$ to $60 \%$ of energy metabolized as protein and $30 \%$ to $60 \%$ as fat. Excess calorie intake can lead to rapid growth in juveniles and obesity in adults [7].
Some species store fat for later uses, such as hibernation and reproduction. The appetite of reptiles that do not hibernate or do not use fat reserves in the reproductive season, increases when the environmental temperature is high, and they do not mobilize fat reserves, which leads to obesity [7].

Obese reptiles store fat in the coelomic, subcutaneous, and parenchymal deposits, and fatty infiltration of organs may occur. Lack of exercise, especially forage activity, is a likely factor in obese animals. Some species are more sedentary than others, such as pythons, boas and vipers [7].

The species under study is commonly sedentary; this strengthen the hypothesis that the animal moved little to feed because it was in an environment with high availability of prey. The accumulation of fat found throughout the coelomic cavity caused the accumulation rate of triglycerides in the hepatocytes to exceed the metabolic degradation rate, resulting in steatosis.

Obesity is a common problem in reptiles kept in captivity, because they usually have available food and little space to move [7]. However, this was observed in the free-living animal in the present study, which was found in an urbanized environment.

Several factors may favor the occurrence of hepatic steatosis in reptiles [8], but the main causes are those related to the metabolic syndrome [9], such as obesity, insulin resistance and hyperlipidemia $[1,12]$. Hepatic alterations caused by infections was the most common in the study specimen, mainly viral - adenovirus that causes hepatitis [13], and arenavirus associated with inclusion bodies in the liver [16]. However, literature about hepatic disorders of non-infectious origin in this species is scarce.

Information on biological and physiological aspects of snakes, and early diagnosis of hepatic alterations favors the appropriate treatment, allowing the prevention of irreversible damage to this organ, and avoid the animal's death.

\section{MANUFACTURER}

${ }^{1}$ SP Labor Comércio de Produtos para Laboratório Ltda. Presidente Prudente, SP, Brazil.

Declaration of interest. The authors report no conflicts of interest. The authors alone are responsible for the content and writing of this paper.

\section{REFERENCES}

1 Bacon B.R., Farahvash M.J., Janney C.G. \& Neuschwander-Tetri B.A. 1994. Nonalcoholic steatohepatitis: an expanded clinical entity. Gastroenterology. 107(4): 1103-1109. 
2 Brown G.P. \& Shine R. 2002. Influence of weather conditions on activity of tropical snakes. Austral Ecology. 27(6): 596-605.

3 Harr K.E., Alleman A.R., Dennis P.M., Maxwell L.K., Lock B.A., Bennett R.A. \& Jacobson E.R. 2001. Morphologic and cytochemical characteristics of blood cells and hematologic and plasma biochemical reference ranges in green iguanas. Journal of the American Veterinary Medical Association. 218(6): 915-921.

4 Huynh M. \& Laloi F. 2013. Diagnosis of liver disease in domestic ferrets (Mustela putorius). Veterinary Clinics: Exotic Animal Practice. 16(1): 121-144.

5 Kolesnikovas C.K.M., Greco K.F. \& Rahme-de-Albuquerque L.C. 2006. Répteis - Ordem Squamata - Subordem Ophidia. In: Cubas Z.S., Silva J.C.R. \& Catão Dias J.L. (Eds). Tratado de animais selvagens - Medicina veterinária. São Paulo: Roca Ltda., pp.68-85.

6 Luiselli L. \& Akani G.C. 2002. Is thermoregulation really unimportant for tropical reptiles? Comparative study of four sympatric snake species from Africa. Acta Oecologica. 23(2): 59-68.

7 Mader D.R. 2006. Nutrition. In: Mader D.R. (Ed). Reptile medicine and surgery. 2nd edn. St. Louis: Elsevier, pp.841-851.

8 Marchesini G., Brizi M., Bianchi G., Tomassetti S., Bugianesi E., Lenzi M., McCullough A.J., Natale S., Forlani G. \& Melchionda N. 2001. Nonalcoholic fatty liver disease: a feature of the metabolic syndrome (Statistical Data Included). Diabetes. 50(8): 1844-2001.

9 Marchiori A. 2013. Tomografia computadorizada no diagnóstico de lipidose hepática em Jabuti-Piranga (Chelonoidis carbonária - SPIX, 1824). 47f. Alegre, ES. Dissertação(Mtrado em Ciências Veterinárias) - Programa de Pós-graduação em Ciências Veterinárias, da Universidade Federal do Espírito Santo.

10 McArthur S., Wilkinson R. \& Meyer J. 2008. Anatomy and physiology. In: McArthur S., Wilkinson R. \& Meyer J. (Eds). Medicine and surgery of tortoises and turtles. Oxford: Blackwell, pp.35-72.

11 McGavin D. 2009. Bases da Patologia em Veterinária. 4.ed. Rio de Janeiro: Elsevier Health Sciences, 1496p.

12 Nasrallah S.M., Wills C.E. \& Galambos J.T. 1981. Hepatic morphology in obesity. Digestive diseases and sciences. 26(4): 325-327.

13 Ramis A., Fernandez-Bellon H., Majo N., Martinez-Silvestre A. Latimer K. \& Campagnoli R. 2000. Adenovirus hepatitis in a boa constrictor (Boa constrictor). Journal of Veterinary Diagnostic Investigation. 12(6): 573-576.

14 Reed R.N. \& Rodda G.H. 2009. Giant constrictors: biological and management profiles and an establishment risk assessment for nine large species of pythons, anacondas, and the Boa constrictor. US Geological Survey, Reston, Virginia, pp.142-186. [Fonte: < https://pubs.usgs.gov/of/2009/1202/pdf/OF09-1202.pdf>]. [Acessed online in July 2017].

15 Silva L.F.N., Riani-Costa C.C.M., Ramos P.R.R. \& Takahira R.K. 2011. Seasonal influence on biochemical profile and serum protein electrophoresis for Boa constrictor amarali in captivity. Brazilian Journal of Biology. 71(2): 517-520.

16Stenglein M.D., Sanders C., Kistler A.L., Ruby J.G., Franco J.Y., Reavill D.R. \& DeRisi J.L. 2012. Identification, characterization, and in vitro culture of highly divergent arenaviruses from boa constrictors and annulated tree boas: candidate etiological agents for snake inclusion body disease. MBio. 3(4): 00180-12. [doi: 10.1128/mBio.00180-12].

17 Tolosa E.M.C., Rodrigues C.J., Behmer O.A. \& Freitas N.A. 2003. Manual de Técnicas para Histologia Normal e Patológica. São Paulo: Manole, 341p. 